\title{
The Influence of Support for Innovation on Organizational Innovation: Taking Organizational Learning as a Mediator
}

\author{
Hsi-Chi Hsiao $\cdot$ Jen-Chia Chang $\cdot$ Su-Chang Chen
}

Published online: 6 October 2013

(c) The Author(s) 2013. This article is published with open access at Springerlink.com

\begin{abstract}
The purpose of this study was to examine the role of organizational learning as a mediator variable between support for innovation and organizational innovation. Samples for this study were randomly selected from 22 technological colleges in Taiwan. The final sample included 322 participants in the full sample which accounted for $58.42 \%$ of the sample. A structural equation modeling (SEM) approach was used to evaluate the complex structure of the proposed research constructs. The study concluded that organizational learning was an important determinant of organizational innovation in technological colleges. Support for innovation had a positive relationship on organizational learning and organizational innovation.
\end{abstract}

Keywords Support for innovation .

Organizational learning · Organizational innovation .

School innovation · Innovation

\section{Introduction}

During the past 50 years, technological and vocational education has made significant contributions to Taiwan's

\section{H.-C. Hsiao}

Graduate Institute of Business and Management, Cheng Shiu University, Kaohsiung, Taiwan

J.-C. Chang $(\square)$

Institute of Technological and Vocational Education, National

Taipei University of Technology, Box 4037, No. 1, Sec. 3,

Chong-Hsiao E. Rd., Taipei, Taiwan

e-mail: jc5839@ntut.edu.tw

S.-C. Chen

Department of Marketing and Logistics Management, National Penghu University of Science and Technology, Penghu, Taiwan economic development by training technical specialists (Ministry of Education 2009). However, with now facing global competition and industrial transformation rapidly, technological education is failing to meet the needs of industry (Hsiao et al. 2010). Enterprises need employees with innovation and creativity. Unfortunately, the graduates of technological colleges do not meet the needs of enterprises. It resulted from technological colleges students' creative and innovative abilities were not as good as before (Hsiao et al. 2009).

Currently, the type of industry has been transferring gradually from labor-intensive to technology-intensive and even knowledge- intensive industry (Ministry of Economic Affairs 2011). This transformation has resulted in rapid changes to Taiwan's industrial structure and technology base that has affected the preparedness of technological college graduates to enter the high-tech workforce (Hsiao et al. 2008). Students' creative and innovative performance can predict individual innovation at work after they graduate from technical college. The education of technological colleges in Taiwan offers students a variety of professional courses and focuses on skills and technical training. It also includes the development of their creative and critical thinking abilities in preparation for the workplace where these skills and abilities are much sought after.

Organizational innovation is one of the most increasingly interesting areas of workforce education (McCharen et al. 2011). One of the most complex settings for organizational change is the school (Bonner et al. 2004). Innovation through creativity is an important factor for the success and competitive advantage of organizations (Woodman et al. 1993). In the management perspective, organizational innovation could be regarded as process innovation and product improvement; and from the educational context standpoint, school innovation could lead school system and 
work process innovation and improving the quality of education and policy (McRoy and Gibbs 2009). Schools need to be more creative and innovative in order to compete, to grow, and to lead. Helping students perform in the realm of creative behavior requires changes in both educational policy and teaching practices (ChanLin et al. 2006). School leaders are providing inspiration and motivation for teachers and teachers are introducing more innovative activities into their classrooms (Hsiao and Chang 2011).

The Taiwan's technological and vocational education system has a similar to general organizations in terms of dynamic work process, complex structure, and systemic connections with both internal and external organizations. Principal is a leader of organization as above, and he/she is the most influential person at school (Wahlstrom and Louis 2008). However, school principals can act in both formal and informal ways to build commitment toward the organization (Hsiao et al. 2010). The principals can interact with supervisors, teachers, parents, and students in a loose organizational structure (Catano and Stronge 2007). The teaching and learning process is the foundation of education. In order to achieve educational goals, the school administrators should endeavor to influence teachers (Olaleye 2008). Principals are expected to exhibit leadership and improve schools to enhance teaching and learning in the school. It is their responsibility to have a positive influence on teacher organization. Wahlstrom and Louis (2008) examined various factors that are often present in principal-teacher interactions relationship to see how these may have an impact on teachers' classroom instructional practices. The results show that increasing our knowledge about what leaders do and how they have an impact on the instructional behaviors of teachers will lead us to a better understanding of how leadership has a direct relationship to improved student achievement. These findings create a clearer picture of teacher-principal interactions that support learning and bring us closer to the elusive goal of clarifying the link between leadership and learning.

For teachers to innovate in organizations, they must engage in continuous learning, whether from students, peers, textbook publications, training experiences, or any other domain. Learning means changing our understanding, and changing understanding is fundamental to innovation (West and Sacramento, 2011). Organizational learning could be defined as a collective and collaborative learning process for dynamic and creative decision making to respond to changes in both internal and external environment of the organization (Argyris and Schon 1996). Organizational learning in schools in the context of education is regarded as a learning community (Imants 2003). The organizational learning emphasizes the importance of interaction that encourages "outward focuses" to bring new knowledge into the organization (Burgoyne et al.
1999). Through interaction with others, teachers not only learn effectively, but also shape their motivation for potential innovation and develop skills in a learning community. Argyris and Schon (1996) asserted that organizational learning enhances the organization's innovative capacity. Most studies regarding organizational learning associate it with organizational innovation (Hsiao et al. 2009; Weerawardena et al. 2006). There is evidence that supportive leadership is positively associated with organizational learning (Lei et al. 1999; Montes et al. 2005; Swiering and Wierdsma 1992; Tushman and Nadler 1986) and innovation (Montes et al. 2005). This support leadership enables the building of teams and provides them with direction, energy, and support for processes of change and increased cohesion (Tushman and Nadler 1986).

School leaders are encouraged to use a range of activities and diverse management strategies to facilitate innovation in teachers (ChanLin et al. 2006). Some studies found that support for innovation may have an influence on organizational innovation (Gumusluoglu and Ilsev 2009a; Hsiao et al. 2010; Scott and Bruce 1994). However, there is a lack of studies examining whether the support for innovation has a direct effect. Empirical studies have not examined the mediating role of this contextual factor while investigating the relationship between organizational learning and support for innovation. Based on the above, this study aimed to explore the impact of support for innovation on organizational innovation and the role played by organizational learning as a mediator variable. Figure 1 shows the model developed for this purpose. According to the proposed model, the perception of support for innovation positively relates to organizational innovation. Organizational learning may mediates this effect.

\section{Literature and Hypotheses}

Support for Innovation and Organizational Innovation

Gumusluoglu and Ilsev (2009b) concluded support for innovation has a moderating role between transformational leadership and organizational innovation. From their results they concluded that transformational leadership and external support for innovation had a significant effect on organizational innovation, but there was no clear evidence

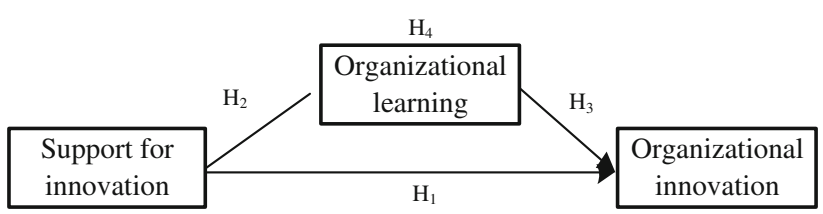

Fig. 1 The Proposed Model 
for internal support for innovation. Eisenbeiss et al. (2008) linked transformational leadership theory to principles of West's (1990) team climate theory and proposed an integrated model for the relationship between transformational leadership and team innovation. This model involves support for innovation as a mediating process and climate for excellence as a moderator. Results from a study of 33 research and development teams confirmed that transformational leadership works through support for innovation, which in turn interacts with climate for excellence such that support for innovation enhances team innovation only when climate for excellence is high. Jung et al. (2003) used a multisource approach to investigate 32 Taiwanese companies, and indicated that transformational leadership had a significant and positive influence on organizational innovation when mediated by empowerment and support for innovation...; "organizational innovation is positively influenced by support for innovation (p. 538)." From the above literature, if there is a supportive atmosphere of innovation, is likely to bring about more organizational innovation. Support for innovation, by implication, should significantly affect organizational innovation. Thus, we propose:

H1 Support for innovation positively influences organizational innovation.

\section{Support for Innovation and Organizational Learning}

Support for innovation includes both the climate for innovation (Siegel and Kaemmerer 1978) and tapping enacted support for innovation (Anderson and West 1998). The climate for innovation, by implication, may be found in personnel documents, policy statements, or conveyed by word of mouth. A necessary condition for organizational innovation is enacted support, as opposed to merely climate support, whereby active support is provided for innovatory behavior. Daft (1986), for example, found that resources needed to be made available to develop innovations and support from the power elite for innovation implementation (Anderson and West 1998). The definition of support for innovation by West (1990), in this study, is an idea of the expectation, approval, and practice support of attempts to introduce new and improved ways of doing things in the work environment (p. 38).

Organizational learning has been regarded as one of the strategic means of archiving long-term organizational success (Senge 1990). Organizational learning can be considered as a process of change in thought and action both shared and individually, which is affected by the organization of the institution (Vera and Crossan 2004). Jung et al. (2009) argue that when an organizational culture values initiative and innovative approaches, employees are more likely to take calculated risks, accept challenging assignments, and derive intrinsic enjoyment from their work. Administrative support for innovation is critical both inside and outside the organization (García-Morales et al. 2008; Burningham and West 1995). If organizational leaders create a work environment supportive of innovation, supervisors may support their staff's empowerment, and staff may respond with increased trust and become more affectively learned and innovative to the organization (Latting et al. 2004). As the model for school innovation that was developed by McCharen et al. (2011), organizational knowledge creation is the critical component for school innovation. In other words, a supportive organizational learning culture positively and significantly impacts departmental creativity and knowledge creation practices in school systems. The environmental aspects increase the chances of developing interdepartmental creative work processes (Nonaka and Takeuchi 1995), which could be foundation for new and innovative knowledge creation practices in the work place (Son and Chermack 2008; McCharen et al. 2011). In this study, support for innovation defines expectations, approval, and practical support of attempts to introduce new and improved ways of doing things in the work environment. Support for innovation, the organizational-level factor, was a good predictor of individual behavior that seems to affect the success of organizational learning. Thus:

H2 Support for innovation positively influences organizational learning

\section{Organizational Learning and Organizational Innovation}

Organizations can learn through collective experience, perspective, and capabilities of individuals (Rait 1995; Song 2008). If innovation is to emerge, organizations need to develop highly effective strategies to improve organizational learning (Glynn 1996). Previous research has shown that organizational learning affects organizational innovation. Hsiao et al. (2009) examined 418 teachers in vocational high schools in Taiwan. They found that the school teachers' perception of higher organizational learning having significant influence on organizational innovation was greater. Liao and Wu (2010) selected samples based on Common Wealth Magazine's Top 1,000 manufacturers and Top 100 financial firms in Taiwan. They came to the conclusion that organizational learning was significantly and positively related to organizational innovation. Weerawardena et al. (2006) examined 1,000 firms in Australia. Their results found that the more the organizational learning, the more the organizational innovation. Wang and Ellinger (2011) were collected 268 senior R\&D project team members who reported their perception about 
the external environment and organizational learning along with 83 R\&D managers who evaluated their employees' innovative behaviors. The results indicated that organizational learning was significant to both individual and organization-level innovation performance and contributed more to the individual-level than organizational innovation performance. Based on these findings, organizational learning and organizational innovation were closely related. Therefore:

H3 Organizational learning positively influences organizational innovation.

From the literature review, support for innovation will affect organizational learning (García-Morales et al. 2008; Jung et al. 2003; Latting 2004). Organizational learning has significant influence on organizational innovation (Hsiao et al. 2009; Liao and Wu 2010; Wang and Ellinger 2011; Weerawardena et al. 2006). Of course, the most direct relationship between variables was support for innovation and organizational innovation; support for innovation also has a positive influence on organizational innovation (Gumusluoglu and Ilsev 2009b; Latting 2004; Scott and Bruce 1994). Organizational learning may be an important mediator variable. This study proposes:

H4 Organizational learning mediates the relationship between support for innovation and organizational innovation.

\section{Method}

Consistent with the two-step approach advocated by Anderson and Gerbing (1988), we estimated a measurement model before examining the structural model relationship. We used Amos 14.0 to estimate the model. Besides providing statistical evidence for running CFA, this study also performed exploratory factor analysis (EFA).

\section{Samples}

Samples from this study were randomly selected from 22 technological colleges in Taiwan. The final sample included 322 teachers in the full sample, which accounted for $58.42 \%$ of the sample. There were 253 male $(78.5 \%)$ and 69 female $(21.5 \%)$ teachers. The average age of subjects in the sample was 43.37 years with a range of 32-62 years. Subjects in the sample were well educated: $2.5 \%$ had bachelor's degrees, $37.7 \%$ had master's degrees, and $31.8 \%$ had PhDs. $4 \%$ had job tenure below 5 years, $20.2 \%$ with job tenure of $6-10$ years, $15.6 \%$ with job tenure of $11-15$ years, and $40.8 \%$ with job tenure above 16 years. The statistics for samples are listed in Table 1 .
Table 1 Statistics of samples

\begin{tabular}{llrl}
\hline Descriptive statistics & Items & Numbers & Percentage \\
\hline Gender & Male & 253 & 78.5 \\
& Female & 69 & 21.5 \\
Education & PhD degree & 102 & 31.8 \\
& Master's degree & 212 & 65.7 \\
& Bachelor's degree & 8 & 2.5 \\
In charge of & Director & 14 & 4.0 \\
Administration & Section head & 121 & 37.7 \\
& Homeroom & 187 & 58.3 \\
Job tenure & teacher & & \\
& Under 5 years & 75 & 23.4 \\
& 6-10 years & 66 & 20.2 \\
& 11-15 years & 50 & 15.6 \\
& 16-20 years & 63 & 19.6 \\
& Over 21 years & 68 & 21.1 \\
\hline
\end{tabular}

$n=322$

Procedure

The purpose of this study was to investigate the relationship between organizational learning and organizational innovation. The role of support for innovation was a mediator variable. Based on the literature review and previous research, hypotheses were formulated and tested. The first section consists of demographic information about the teachers among the 22 technological colleges in Taiwan. The second section consists of 16 items within 3 scales. All scales were composed of 5-point Likert-type items. The average time for completing each questionnaire was 10-15 min.

\section{Measures}

Tests of the instrument items' reliability and validity of the measurement construct are required prior to any further analyses to increase statistical acceptability of the proposed measurement model (Thompson 2004). To estimate the measurement model, we employed CFA to test the fit of scales separately. After the test of measurement model, the item will be deleted if the item is unacceptable. In the meanwhile, validity and reliability can be constructed in the measurement model for each scale. In addition, overall CFA was used to insure the validity issue of proposed measurement model (Kline 2005; Thompson 2004). These item-related reliability and construct-related validity issues were examined to insure the overall quality of data analysis results.

\section{Support for Innovation}

Support for innovation (SIS) was measured by seven items to which respondents were asked to respond on a 5-point "strongly disagree" to "strongly agree" scale. The scale 
was originally developed by Siegel and Kaemmerer (1978) and modified by Scott and Bruce (1994). Sample items were "Creativity is encouraged here", "Our ability to function creatively is respected by the leadership," and "The main function of members in this organization is to follow orders which come down through channels." Testing the one-factor model (CFA), resulted in a good fit index $\left(\chi^{2} / \mathrm{df}=1.91, \quad\right.$ GFI $=.995, \quad$ AGFI $=.978, \quad$ RMSEA $=$ $\left..052, \rho_{\mathrm{c}}=.85, \mathrm{AVE}=.76\right)$.

\section{Organizational Learning}

After reviewing how organizational learning is measured in different studies of related research, e.g., Kale et al. (2000), Edmondson (1999), we drew up a four-item scale to measure organizational learning. We developed a confirmatory factor analysis (CFA) to validate our scale and showed that the four-item scale was unidimensional with high reliability $(\alpha=.92$, AVE $=.70)$. Scales that measure organizational learning based on the main participants have been widely used in recent studies (e.g., Bauer and Mulder 2013; Chang et al. 2011; García-Morales et al. 2006; Hsiao and Chang 2011; Rhee and Sigler 2010).

All items were rated using a 5-point scale ranging from 1 ("Very strongly disagree") to 5 ("Very strongly agree"). Sample items were "The organization has acquired and used much new and relevant knowledge that provided a competitive advantage over the past three years", "The organization was a learning organization," and "The educational center greatly encourages the acquisition, sharing, dissemination and application of knowledge, and learning among its different members." Internal consistency was measured with Cronbach's $\alpha(\alpha=.92)$. A CFA of a one-factor model reflected acceptable goodness-of-fit indexes $\left(\chi^{2} / \mathrm{df}=3.83\right.$, GFI $=$ .994, AGFI $=.973$, RMSEA $=.040, \rho_{\mathrm{c}}=.90, \mathrm{AVE}=.70$ ).

\section{Organizational Innovation}

The Organizational Innovation Scale (OIS) was measured with five items adapted from Friedman (2003). All items were rated using a 5-point scale ranging from 1 ("Very strongly disagree") to 5 ("Very strongly agree"). Sample items were "Teachers often introduce new ideas for school improvement and change", "School administration encourages teachers to seek new directions and challenges in teaching," and "Social and recreational activities are organized for teachers and other staff members." It was suggested that one item from OIS be removed on the basis of an EFA, due to high structure coefficients loading above 1 (Hair et al. 2010). Cronbach's $\alpha$ reflected a good level of internal consistency $(\alpha=.88)$. A CFA test of one-factor model resulted in suitable goodnessof-fit indexes $\left(\chi^{2} / \mathrm{df}=1.86, \mathrm{GFI}=.998, \quad \mathrm{AGFI}=.988\right.$, RMSEA $\left.=.022, \rho_{\mathrm{c}}=.86, \mathrm{AVE}=.68\right)$.

\section{The EFA for Scales}

After establishing the measuring constructs according to the original definition of the three measures, support for innovation, organizational innovation, and organizational learning, EFA is conducted to determine if there are other hidden factors. Table 2 displays the loading of one factor obtained by EFA. As seen in Table 2, there is only one factor with eigenvalue $\lambda$ greater than 1 in each scale. In view of the discrepancy between the distribution of questions and the original definition of variables, there is no item requiring deletion. As seen in the above reliability analysis as shown in Table 3, the Cronbach's $\alpha$ of the construct are all above 0.7 , revealing that the questionnaire can be a valid measure for the three variables.

\section{Results}

Item internal consistency estimates and general zero-order item correlation coefficient estimates were considered for item reliability. Table 3 shows basic descriptive summary statistics of the responses and the Cronbach's $\alpha$ estimates of the research construct items. Following the first item in the data analysis strategy, item internal consistency and measurement model construct validity were insured through the use of scale reliability, zero-order correlation coefficient estimates, and CFA. Means and standard deviations of SI, OL, and OI are represented in Table 3. All mean scores were $>3.0$, ranging from 3.77 to 3.82 . This indicated an overall positive perception. According to reliability results, all items for each research construct were found to be statistically reliable based on the coefficient estimates (ranges from 0.85 to 0.92 ).

\section{Correlation Analysis}

The bivariate correlation analysis is presented in Table 4 . Organizational learning had a significant and positive correlation for support for innovation $(r=.732, p<.01)$

Table 2 EFA of measurement model for scales

\begin{tabular}{lcll}
\hline No. & $\begin{array}{l}\text { Support for } \\
\text { innovation }\end{array}$ & $\begin{array}{l}\text { Organizational } \\
\text { learning }\end{array}$ & $\begin{array}{l}\text { Organizational } \\
\text { innovation }\end{array}$ \\
\hline 1 & .543 & .648 & .542 \\
2 & .600 & .743 & .681 \\
3 & .667 & .556 & .635 \\
4 & .616 & .584 & .646 \\
5 & .595 & & .544 \\
6 & .557 & & \\
7 & .564 & & 3.032 \\
Eigenvalue $(\lambda)$ & 4.037 & 2.770 & \\
\hline
\end{tabular}


Table 3 Statistics and reliability coefficient for each subscale

\begin{tabular}{lllll}
\hline Subscale & $\begin{array}{l}\text { Number } \\
\text { of items }\end{array}$ & Mean & SD & Cronbach $\alpha$ \\
\hline Support for innovation (SI) & 7 & 3.78 & .62 & .85 \\
Organizational learning (OL) & 4 & 3.82 & .67 & .92 \\
Organizational innovation (OI) & 5 & 3.80 & .63 & .88 \\
\hline
\end{tabular}

$n=322$

Table 4 Correlation coefficients for pairs of variables

\begin{tabular}{llll}
\hline Subscale & SI & OL & OI \\
\hline Support for innovation (SI) & - & & \\
Organizational learning (OL) & $.732^{* *}$ & - & \\
Organizational innovation (OI) & $.718^{* *}$ & $.726^{* *}$ & - \\
\hline$n=322, * * p<.01$ & & &
\end{tabular}

and organizational innovation $(r=.718, p<.01)$. Support for innovation had a significant and positive correlation with organizational innovation $(r=.726, p<.01)$. Variable correlations are shown in Table 4 . Teachers who had positive perception in support for innovation were also likely to lead to more positive experience in organizational learning. It seems that teachers who had more frequently engaged in organizational learning behaviors tended to engage more frequently in organizational innovation. Organizational learning is increasingly becoming recognized as a crucial organizational function. However, teachers who had positive perception toward support for innovation had a better tendency to practice organizational innovation.

\section{Analysis Model}

Zero-order correlation analysis showed statically acceptable correlation coefficient estimates at a $p$ value of less than 0.001 , which is a higher than moderate level coefficient, among the research constructs ( $r$ ranges from 0.718 to 0.732 , see Table 4). All the statistically acceptable levels of correlations supported acceptable reliability among the research constructs. Secondly, CFA was conducted. In accordance with standard structural equation modeling (SEM) practices, path coefficient estimates and structural model-fit indices were the primary considerations (Bentler 1990). Running a single full CFA is necessary; the structural model can also be examined by SEM in this study. All employed measures were validated in the literature and developed based on the theoretical foundation, thus providing statistical evidence for running CFA. Tables 5 and 6 present CFA results with multiple model-fit to data indices, which include general Chi square estimate, goodness-of-fit
(GFI), comparative fit index (CFI), and non-normed fit index (NNFI), as well as two error variance indicators of root mean square residual (RMR) and root mean square error approximation (RMSEA).

Using organizational innovation as the endogenous variable, and support for innovation and organizational learning as exogenous variables, each path in the model was tested. The first goal was to estimate the predictive power of the set of independent variables on organizational innovation. As the focus of this study was on the direct and indirect effects of organizational learning on organizational innovation, the strength of predictor variables on the dependent variable was assessed. All the indices were in line with recommended benchmarks for acceptable fit $\left(\chi^{2} / \mathrm{df}<2.205\right.$, GFI $=.962$, AGFI $=.940$, and RMSEA $=.051)$. The total explained variance in organizational innovation was $69.2 \%$ $\left(R^{2}=.692\right)$. Table 5 illustrates the fit indices for the proposed research model.

Table 6 shows the structural model with the standardized coefficients for the research sample. The results in Table 6 provide sufficient support for $\mathrm{H}_{1}$. Support for innovation is significantly and positively related to organizational innovation, $\gamma_{1}=.789, p<.001$. Table 6 also supports $\mathrm{H}_{2}$ and $\mathrm{H}_{3}$. Support for innovation is significantly and positively related to support for innovation, $\gamma_{2}=.776$, $p<.001$. Support for innovation is significantly and positively related to organizational innovation, $\beta_{1}=.426$, $p<.001$. From Tables 5 and 6 , we can see that the results of the full examination model and all indexes show very good fit with the model.

Finally, this study was measured using path analysis to show direct and indirect effects of each construct. The results are reported in Table 7. After analysis, the direct effect of organizational learning and support for innovation, $\gamma_{1}=.354, p<.001$, is significant. The indirect effect is $.435, p<.001$ as shown in Fig. 2. The indirect effect is greater than the direct effect. Therefore, organizational learning mediated the relationship between support for innovation and organizational innovation. $\mathrm{H}_{4}$ is supported.

Table 5 Summary of goodness-of-fit indices $(\mathrm{df}=51)$

\begin{tabular}{llc}
\hline Fit index & $\begin{array}{l}\text { Recommended } \\
\text { level of fit }\end{array}$ & $\begin{array}{l}\text { Proposed research } \\
\text { mode }\end{array}$ \\
\hline$\chi^{2}$ & n.s at $p<.05$ & 112.465 \\
$\chi^{2} / \mathrm{df}$ & $<5$ & 2.205 \\
AGFI & $>.90$ & .940 \\
NFI & $>.90$ & .970 \\
CFI & $>.90$ & .984 \\
RMSEA & $<.05$ & .051 \\
RMR & $<.05$ & .028 \\
\hline
\end{tabular}


Table 6 Structural parameter estimates and goodness-of-fit indices

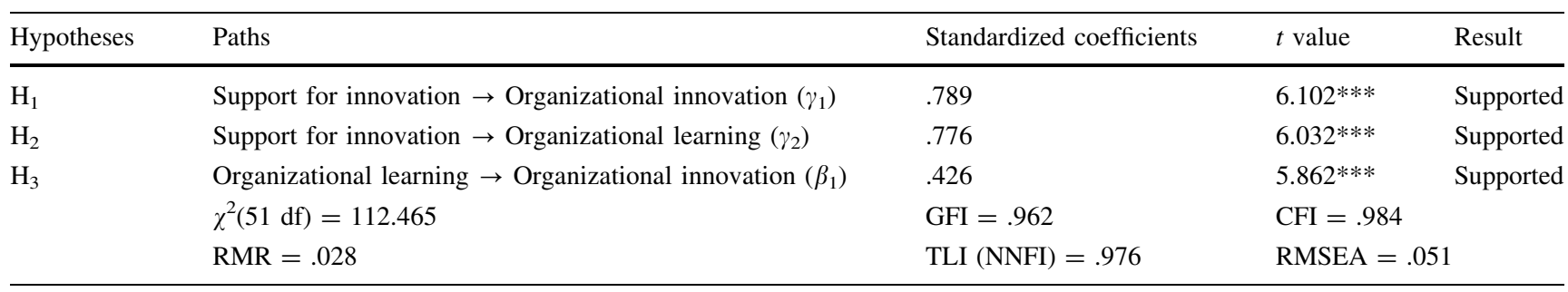

$* * * p<.001$

\section{Discussion}

This study was aimed at examining the impact of support for innovation on organizational innovation and the role played by organizational learning as mediating variables. First, results indicated that support for innovation had a direct positive influence on organizational innovation. This result concurred with Gumusluoglu and Ilsev (2009b), and

Table 7 Direct and indirect relationship

\begin{tabular}{|c|c|c|}
\hline \multirow[t]{2}{*}{ Variables } & \multicolumn{2}{|l|}{ Endogenous } \\
\hline & $\begin{array}{l}\text { Organizational } \\
\text { learning } \\
\text { effect }\end{array}$ & $\begin{array}{l}\text { Organizational } \\
\text { innovation } \\
\text { effect }\end{array}$ \\
\hline \multicolumn{3}{|c|}{ Exogenous } \\
\hline \multicolumn{3}{|c|}{ Support for innovation } \\
\hline Direct & $.776 * * *$ & $.354 * * *$ \\
\hline Indirect & - & $.435 * * *$ \\
\hline Total & $.776 * * *$ & $.789 * * *$ \\
\hline \multicolumn{3}{|c|}{ Exogenous } \\
\hline \multicolumn{3}{|c|}{ Organizational learning } \\
\hline Direct & & $.426 * * *$ \\
\hline Indirect & & - \\
\hline Total & & $.426 * * *$ \\
\hline
\end{tabular}

$* * * p<.001$

Fig. 2 Path coefficients of the research model
Scott and Bruce (1994) whose study showed the greater support for innovation, the greater organizational innovation. It was important to show empirically that the effect of administration on organizational innovation increased with significant support for innovation.

Second, the results of the structural equation model indicated that support for innovation had a positive influence on organizational learning. That is, with greater support for innovation, there is more organizational learning. Organizations can learn through collective experience, perspective, and capabilities of individuals (Rait 1995). Therefore, organizational leaders may create a work environment supportive of innovation, like as Latting et al. (2004) emphasized, supervisors or department chiefs may support their staff's empowerment, and staff may become more affectively learned (Latting et al. 2004). Third, the results provided sufficient evidence to support a relationship between organizational learning and organizational innovation. This empirical evidence implies that organizational learning affects organizational innovation. In other words, higher organizational learning leads to improved organizational innovation. Accordingly, this finding is consistent with the research by Liao et al. (2008) and Liao and $\mathrm{Wu}(2010)$.

Fourth, the hypothesized mediator role of organizational learning was confirmed. Empirical evidence indicates that the relationship between support for innovation and

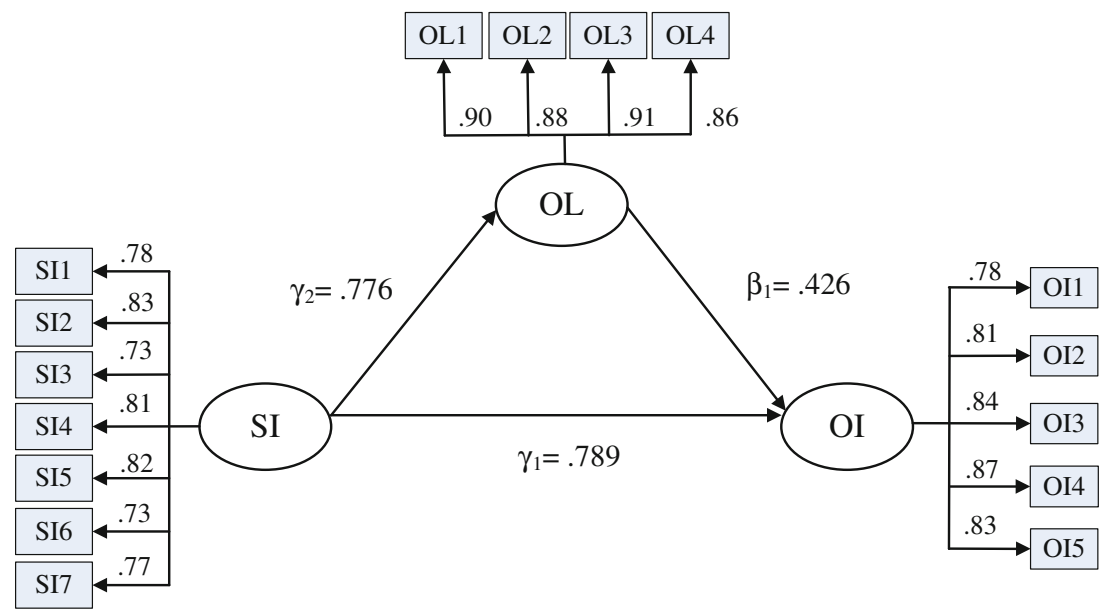


organizational innovation is significant where the direct effect is less than the indirect effect. Organizational learning triggers the relationship between support for innovation and organizational innovation. In the study of Hsiao and Chang (2011) found that there is the mediate effect of organizational learning on the relationship between organizational learning and organizational innovation. This study not only found a similar result, but further support for innovation can also, through organizational learning, directly or indirectly improve organizational innovation.

\section{Limitation}

There are several limitations to the present study. The role of organizational learning as a mediator between support for innovation and organizational innovation was investigated. The results indicated that organizational learning served as a partial mediator. Other contextual variables were not included in the study.

The second limitation is related to the survey data. The survey data may have been subject to social desirability bias. This bias occurs in survey research when participants answer the questions to conform to social norms or expectations. In particular, some of these samples were collected from teachers in charge of administration in technological colleges. Their efforts are a possible determinant of innovation performance in schools. They know more about the organizational innovation in schools than homeroom teachers (e.g., general teachers without administrative duties or responsibilities). However, their perceptions of self-assessment may have a tendency to overestimate organizational innovation. The third limitation of this study is related to the participants. Participants consisted of 322 teachers only from technological colleges in Taiwan. Because it is a sampling from a selection of people in a specific kind of school, findings cannot be generalized to larger populations. For this reason, future research can be conducted with a collection of more samples from different groups of teachers and areas of study to broaden the scope. This may include teacher trainers, students, and parents.

\section{Directions for Further Research}

There are several suggestions for future research. First, this study examines only the role of support for innovation, organizational learning, and organizational innovation. This study indicates that support for innovation is a key factor in organizational innovation. It is possible that there are other variables not included in this study. Future research should further explore the perceptions of organizational climate, organizational behavior, and the administrative-teacher exchange relationship. This study investigated the relationship between the support for innovation and organizational innovation, and organizational learning as the mediator. There may be other factors that affect organizational innovation. Future research should not only explore relevant variables, but also attempt to investigate interactions between group-level variables and individual-level variables. In addition, future research can be conducted with a larger sample across different levels or groups to provide more varied results.

\section{Conclusions}

This study explored the relationship among support for innovation, organizational learning, and organizational innovation. The results indicated that the support for innovation and organizational learning are both important determinants of organizational innovation in technological colleges. School principals played a key role in school improvement (Marks and Printy 2003). The results also suggest that successful organizational innovation requires strong support for innovation in the school improvement process. As Bolívar and Moreno (2006) pointed out, the principal is about improving teaching and learning, and should be geared toward the creation of the right conditions for learning, framed into clear expectations of what should be achieved. Principals may often support and encourage their staff in an innovative setting with strategies for organizational innovation. In addition, the study also suggests that in order to improve organizational innovation in technological colleges, future studies could investigate the effects of other contextual variables such as organizational climate, team cohesion, and leader-member exchange.

This research examined the influence of support for innovation and organizational learning on organizational innovation. The findings revealed that organizational learning acted as a mediator of the relationship between support for innovation and organizational innovation. At the same time, school principals played a central role in enhancing organizational innovation (McCharen et al. 2011). This study also found that when school principals used support for innovation through organizational learning, support for innovation would be a highly effective way to achieve organizational innovation in the technological colleges.

According to MOI statistics, Taiwan's total fertility rate has dropped to $0.9 \%$ (MOI 2012). As for the number of senior high school students, the statistics of MOI (2012) reported that there were 956,823 in 2002 and 873,220 in 2012 (MOI 2012). Typically, about $60 \%$ of senior high school graduates will enter technological colleges in Taiwan. There was a decrease of 83,603 students from 2002 to 2012, equivalent to the enrollment of about 20 schools, and the number of students continues to decline. In response to 
this challenge, school principals interested in support for innovation and associated organizational innovation have become more focused on school management. Schools must change and develop in order to survive and to remain effective because of the increasingly rapid pace of innovation (Kursunoglu and Tanriogen 2009). However, the behaviors of school principals and teachers occur in a far more complex environment involving many additional factors (Hsiao and Chang 2011). Thus, this study suggests that more insight is necessary into the influence of these factors through measurement of such aspects as the type of leader effectiveness, organizational climate and culture, team/group cohesion, perceived organizational support, and perceived supervisor support.

Organizational learning has focused on collective attention and learning among members when they seek continuous improvement for students, themselves, and the organization (Collinson et al. 2006). Thus, the results of this study suggest that successful organizational innovation requires strong support for innovation at all levels. If the support for innovation and organizational learning were implemented properly, schools would have the capacity to better help organizational innovation.

Open Access This article is distributed under the terms of the Creative Commons Attribution License which permits any use, distribution, and reproduction in any medium, provided the original author(s) and the source are credited.

\section{References}

Anderson, J. C., \& Gerbing, D. W. (1988). Structure equation modeling in practice: A review and recommended two-step approach. Psychological Bulletin, 103(3), 411-423.

Anderson, N. R., \& West, M. A. (1998). Measuring climate for work group innovation: Development andvalidation of the Team Climate Inventory. Journal of Organizational Behavior, 19, 235-258.

Argyris, C., \& Schon, D. A. (1996). Organization learning II: Theory, method, and practice (Vol. 1). Boston, MA: Addison-Wesley.

Bauer, J., \& Mulder, R. H. (2013). Engagement in learning after errors at work: Enabling conditions and types of engagement. Journal of Education and Work, 26(1), 99-119.

Bentler, P. M. (1990). Comparative fit indexes in structural models. Psychological Bulletin, 107(2), 238-246.

Bolı'var, A., \& Moreno, J. M. (2006). Between transaction and transformation: The role of school principals as education leaders in Spain. Journal of Educational Change, 7(1-2), 19-31. doi:10.1007/s10833-006-0010-7.

Bonner, M., Koch, T., \& Langmeyer, D. (2004). Organizational theory applied to school reform. School Psychology International, 25(4), 455-471.

Burgoyne, J., Pedler, M., \& Boydell, T. (1999). The learning company, a strategy for sustainable development. New York: Maidenhead.

Burningham, C., \& West, M. A. (1995). Individual, climate and group interaction processes as predictors of work team innovation. Small Group Research, 26(1), 106-117.
Catano, N., \& Stronge, J. H. (2007). What do we expect of school principals? Congruence between principal evaluation and performance standards. International Journal of Leadership in Education, 10(4), 379-399.

Chang, J.-C., Hsiao, H.-C., \& Tu, Y.-L. (2011). Besides using transformational leadership, what should schools do to achieve innovation? Asia-Pacific Education Researcher, 20(1), 48-60.

ChanLin, L., Hong, J., Horng, J., Chang, S., \& Chu, H. (2006). Factors influencing technology integration in teaching-A Taiwanese perspective. Innovations in Education and Teaching International, 43(1), 57-68.

Collinson, V., Cook, T. F., \& Conley, S. (2006). Organizational learning in schools and school systems: Improving learning, teaching, and leading. Theory into Practice, 45(2), 107-116.

Daft, R. L. (1986). A dual-core model of organizational innovation. Academy of Management Journal,21(2), 193-210.

Edmondson, A. C. (1999). Psychological safety and learning behaviour in work teams. Administrative Science Quarterly, 44, 350-394.

Eisenbeiss, S. A., van Knippenberg, D., \& Boerner, S. (2008). Transformational leadership and team innovation: Integrating team climate principles. Journal of Applied Psychology, 93(6), $1438-1446$.

Friedman, I. A. (2003). School organizational values: The driving force for effectiveness and change. In P. T. Begley \& O. Johansson (Eds.), The ethical dimensions of school leadership (pp. 161-179). Dordrecht: Kluwer Academic Publishers.

García-Morales, V. J., Llorens-Montes, F. J., \& Verdú-Jover, A. J. (2008). The effects of transformational leadership on organizational performance through knowledge and innovation. British Journal of Management, 19(4), 299-319.

García-Morales, V. J., Lopez-Martin, F. J., \& Llamas-Sanchez, R. (2006). Strategic factors and barriers for promoting educational organizational learning. Teaching and Teacher Education, 22(4), $478-502$.

Glynn, M. A. (1996). Innovative genius: A framework for relating individual and organizational intelligences to innovation. Academy of Management Review, 21(4), 1081-1111.

Gumusluoglu, L., \& Ilsev, A. (2009a). Transformational leadership, creativity, and organizational innovation. Journal of Business Research, 62(4), 461-473.

Gumusluoglu, L., \& Ilsev, A. (2009b). Transformational leadership and organizational innovation: The roles of internal and external support for innovation. The Journal of Product Innovation Management, 26, 264-277.

Hair, J. F., Black, W. C., Babin, B. J., \& Anderson, R. E. (2010). Multivariate data analysis: A global perspective (7th ed.). Upper Saddle River, NJ: Pearson Prentice Hall.

Hsiao, H. C., \& Chang, J. C. (2011). The role of organizational learning in transformational leadership and organizational innovation. Asia Pacific Education Review, 12(4), 621-631.

Hsiao, H. C., Chang, J. C., \& Tu, Y. L. (2009). The influence of the transformational leadership and organizational learning on organizational innovation for electrical and electronic cluster of vocational high school teachers: A Taiwanese perspective. In Proceedings of 2009 international conference on social science and humanities, Singapore 9-11 October (pp. 144-148).

Hsiao, H. C., Chang, J. C., \& Tu, Y. L. (2010). Support for innovation, organizational learning, and organizational innovation in the vocational high schools: A Taiwanese perspective. International Journal of Technology and Engineering Education, 7(2), 11-16.

Hsiao, H. C., Chen, M. N., \& Yang, H. S. (2008). Leadership of vocational high school principals in curriculum reform: A case study in Taiwan. International Journal of Educational Development, 28, 669-686. 
Imants, J. (2003). Two basic mechanisms for organizational learning in schools. European Journal of Teacher Education, 26(3), 293-311.

Jung, D. I., Chow, C., \& Wu, A. (2003). The role of transformational leadership in enhancing organizational innovation: Hypotheses and some preliminary findings. The Leadership Quarterly, 14, $525-544$

Jung, D., Yammarino, F. J., \& Lee, J. K. (2009). Moderating role of subordinates' attitudes on transformational leadership and effectiveness: A multi-cultural and multi-level perspective. The Leadership Quarterly, 20, 586-603.

Kale, P., Singh, J., \& Perlmutter, H. (2000). Learning and protection of assets in strategic alliance: Building relationship capital. Strategic Management Journal, 21(3), 217-237.

Kline, R. B. (2005). Principles and practices of structural equation modeling (2nd ed.). New York: The Guilford Press.

Kursunoglu, A., \& Tanriogen, A. (2009). The relationship between teachers' perceptions towards instructional leadership behaviors of their principals and teachers' attitudes towards change. Procedia-Social and Behavioral Sciences, 1(1), 252-258.

Latting, J. K., Beck, M. H., Slack, K. J., Tetrick, L. E., Jones, A. P., Etchegaray, J. M., et al. (2004). Promoting service quality and client adherence to the service plan: The role of top management's support for innovation and learning. Administration in Social Work, 28(2), 29-48.

Lei, D., Slocum, J. W., \& Pitts, R. A. (1999). Designing organizations for competitive advantage: The power of unlearning and learning. Organizational Dynamics, 27(3), 24-38.

Liao, S. H., Fei, W. C., \& Liu, C. T. (2008). Relationship between knowledge inertia, organizational learning and organizational innovation. Technovation, 28, 183-195.

Liao, S. H., \& Wu, C. C. (2010). System perspective of knowledge management, organizational learning, and organizational innovation. Expert Systems with Applications, 37(2), 1096-1103.

Marks, H. M., \& Printy, S. M. (2003). Principal leadership and school performance: An integration of transformational and instructional leadership. Educational Administration Quarterly, 39(3), 370-397.

McCharen, B., Song, J. H., \& Martens, J. (2011). School innovation: The mutual impacts of organizational learning and creativity. Educational Management Administration and Leadership, 39(6), 676-694.

McRoy, I., \& Gibbs, K. S. (2009). Leading change in higher education. Educational Management and Administration, 37(5), $687-704$

Minister of Education. (2009). Technological and vocational education reform project-expertise training. Retrieved December 16, 2011 from http://english.education.edu.tw/ct.asp?xItem=11137 $\& \mathrm{ctNode}=504 \& \mathrm{mp}=12$.

Ministry of Economic Affairs. (2011). White book of small business. Small and Medium Enterprise Administration, Ministry of Economic Affairs, Taiwan. Retrieved Nov. 30, 2011 from http://www.moeasmea.gov.tw/ct.asp?xItem $=9654 \&$ CtNode $=1089$ $\& m p=1$.

MOI. (2012). The demographic statistic information in Taiwan. Ministry of the Interior, Taiwan. Retrieved from http://sowf.moi. gov.tw/stat/week/list.htm.

Montes, F. J. L., Moreno, A. R., \& Morales, V. G. (2005). Influence of support leadership and teamwork cohesion on organizational learning, innovation and performance: An empirical examination. Technovation, 25(10), 1159-1172.

Nonaka, I., \& Takeuchi, H. (1995). The knowledge-creating company: How Japanese companies create the dynamics of innovation. New York: Oxford University Press.

Olaleye, F. O. (2008). Principal's leadership behaviour and school learning culture in secondary schools in Ekiti-State Nigeria. Pakistan Journal of Social Sciences, 5(9), 856-860.

Rait, E. (1995). Against the current: Organizational learning in school. In S. B. Bacharach \& B. Mundell (Eds.), Images of schools: Structures and roles in organizational behaviour (pp. 71-107). Thousand Oaks, CA: Corwin Press.

Rhee, K. S., \& Sigler, T. H. (2010). Developing enlightened leaders for industry and community: Executive education and servicelearning. Journal of Management Education, 34(1), 163-181.

Scott, S. G., \& Bruce, R. A. (1994). Determinants of innovative behaviour: A path model of individual innovation in the workplace. Academy of Management Journal, 37(3), 580-607.

Senge, P. M. (1990). The fifth discipline: The art and practice of the learning organization. New York: Doubleday.

Siegel, S., \& Kaemmerer, W. (1978). Measuring the perceived support for innovation in organizations. Journal of Applied Psychology, 63, 553-562.

Song, J. H. (2008). The effect of learning organization culture on the practices of human knowledge-creation: An empirical study in Korea. International Journal of Training and Development, 12(4), 265-281.

Swiering, J., \& Wierdsma, A. (1992). Becoming a learning organization: Beyond the learning curve. Reading, MA: AddisonWesley.

Thompson, B. (2004). Exploratory and confirmatory factor analysis: Understanding concepts and applications. Washington, DC: American Psychological Association.

Tushman, M. L., \& Nadler, D. A. (1986). Organization for innovation. California Management Review, 28(3), 74-92.

Vera, D., \& Crossan, M. (2004). Strategic leadership and organizational learning. Academy of Management Review, 29, 222-224.

Wahlstrom, K. L., \& Louis, K. S. (2008). How teachers experience principal leadership: The roles of professional community, trust, efficacy, and shared responsibility. Educational Administration Quarterly, 44(4), 458-495.

Wang, Y.-L., \& Ellinger, A. D. (2011). Organizational learning: Perception of external environment and innovation performance. International Journal of Manpower, 32(5), 512-536.

Weerawardena, J., O'Cass, A., \& Julian, C. (2006). Does industry matter? Examining the role of industry structure and organizational learning in innovation and brand performance. Journal of Business Research, 59, 37-45.

West, M. A. (1990). The social psychology of innovation in groups. In M. A. West \& J. L. Farr (Eds.), Innovation and creativity at work: Psychological and organizational strategies (pp. 309-333). Chichester: Wiley.

West, M. A., \& Sacramento, C. A. (2011). Flourishing in teams: Developing creativity and innovation. In J. Henry (Ed.), Creative management and development (3rd ed., pp. 25-43). London: Sage.

Woodman, R. W., Sawyer, J. E., \& Griffin, R. W. (1993). Toward a theory of organizational creativity. The Academy of Management Review, 18(2), 293-321. 